\title{
Women's Engagement with Humanist, Spiritual and Religious Meaning-Making in Prison: A Longitudinal Study of Its Impact on Recidivism
}

\author{
Jeff Duncan ${ }^{1}$, Richard Stansfield ${ }^{2}$, Steve Hall ${ }^{3}$ and Tom O'Connor ${ }^{4, *}$ \\ 1 Oregon Department of Corrections, Salem, OR 97301-4667, USA; Jeff.B.Duncan@doc.state.or.us \\ 2 Faculty of Sociology, Anthropology \& Criminal Justice, Rutgers University, \\ New Brunswick, NJ 08901-8554, USA; Richard.Stansfield@rutgers.edu \\ 3 Independent Correctional Consultant, Tom O'Connor, 1420 Court St. NE., Salem, OR 97301, USA; \\ stevehall212@gmail.com \\ 4 Transforming Corrections, Steve Hall 84A Vale Road, St Heliers, Auckland 1071, New Zealand \\ * Correspondence: oconnortom@aol.com; Tel.: +1-503-559-5752
}

Received: 20 April 2018; Accepted: 22 May 2018; Published: 25 May 2018

\begin{abstract}
This study explores the long-term impact on recidivism of the engagement of over 300 women prisoners with humanist, spiritual and religious ways of making meaning during their incarceration. Prison chaplains and community volunteers in the Oregon Department of Corrections offered a diverse range of humanist, spiritual and religious (HSR) events to the women, and 95\% of them voluntarily engaged at varied levels with an average participation rate of about $3 \mathrm{~h}$ per month. The women who attended most often were motivated to do so by intrinsic or meaning-driven reasons and were more likely to have listened to a religious program on radio or TV in the six months before their incarceration. Controlling for ethnicity, risk of recidivism, participation in other programs (education, substance use, cognitive and work), length of time incarcerated, and infractions during incarceration we found an overall significantly positive impact of HSR involvement on recidivism during the first year after release and over a 13-year follow-up period post prison. The impact was concentrated among the $20 \%$ of women who attended most frequently ( 4 or more hours per month) indicating a dosage and consistency of practice effect. Prison chaplains and volunteers make a valuable contribution to the lives of women in prison and to the correctional system; the pro-social support/modeling and diverse help with meaning-making they offer in prison has a positive influence on the women's journey of desistance in the community after prison.
\end{abstract}

Keywords: women; prison; humanism; spirituality; religion; chaplain; volunteer; meaning; desistance; recidivism

\section{Introduction}

At a time of growing prison costs and incarceration for women; with little sense of a positive return on investment; there is increasing need for every part of the prison system security; management and programming operations to show a tangible community benefit from its work. Prison chaplaincy and volunteer programs are not exempt from this need to demonstrate relevancy to the correctional mission of helping people to lower their risk, foster their prosocial skills/support and prevent post prison recidivism in a cost-effective way. In 2004 we began collecting data on the engagement of 349 women prisoners in Oregon with humanist; spiritual and religious ways of making meaning during their incarceration. In 2011 we published an article in the journal Religions called The Sociology of Humanist, Spiritual, and Religious Practice in Prison: Supporting Responsivity and Desistance from Crime that described the sociology of that engagement (O'Connor and Duncan 2011). Now, having 
followed the women for up to 13 years post release we present our findings on the impact of that engagement on recidivism.

In his acclaimed book, A Secular Age, the Canadian philosopher Charles Taylor describes what it means to live in a modern secular democracy. For Taylor, every person now has choices around how they create a sense of ultimate meaning in their life; how they relate to the challenging human questions of suffering, evil, death, health, purpose, justice and love. The more traditional choice is the "religious" path that derives meaning from within one of a diverse range of religious traditions, all of which posit a transcendent source or ground of meaning usually called God or the Divine. Now that we live in a secular age, however, people can and increasingly do choose to make meaning in ways that make no reference to a transcendent God/Divinity, but only to human life and the human condition. This purely secular or "humanistic" way of making meaning only emerged in the last few hundred years; historically, this choice did not exist on a broad societal level. Nowadays most people take the humanist choice for granted (Taylor 2007). In his book "Good without God: What a Billion Nonreligious People Do Believe" Greg Epstein, the humanist chaplain at Harvard University, shows how the secular choice is not about the absence or lack of faith or belief, rather it is a faith and belief in human life as the source of goodness and meaning (Epstein 2009). The third broad avenue for making meaning is the "spiritual" path in which people retain the concept of a transcendent source of meaning beyond the bounds of human life, but eschew any organized religious dimension to their meaning-making. People who are spiritual retain a sense of God, the Divine, or Transcendence beyond human life, but find it difficult to relate to or derive meaning within the context of the sources and practices of an organized religion (Taylor 2007). Researchers who study the impact of religion on well-being have found it helpful to distinguish spirituality from religion in this way (Hill and Pargament 2013; Idler et al. 2003), and Jang and Franzen (2013) have urged criminologists to add these kinds of distinctions to their study of religion and crime. We call these three paths of meaning-making: humanist; spiritual; and religious or HSR for short.

Most people serving a prison sentence are faced with a crisis or challenge of meaning in their lives that stems from the many losses they experience such as freedom, social status, family, sexual expression, and choice as well as from the need to construct a more complex way of relating to the world that will give them a new sense of identity, belonging, purpose and value even as they struggle with their feelings around loss, shame, guilt, anger, and regret. Prison chaplains have the potential and the calling to help people work through this existential crisis-opportunity and develop meaning within the context of the particular humanist, spiritual or religious path to which they are drawn. The training, skills, resources and role of prison chaplains make them uniquely suited to assess, support and challenge people as they navigate this task of meaning-making. Prison chaplains work for government prison systems, and because their role straddles both church and state they need to be able to work competently with all three systems of meaning-making. The first amendment against governmental establishment or restriction of religion calls prison chaplains to some very skillful and nuanced work; they must foster every prisoner's unique journey of meaning-making without using their government position to favor their own or any particular version of humanism, spirituality or religion ( $\mathrm{O}^{\prime}$ Connor et al. 2006).

\section{Oregon's HSR Model}

Women and men in Oregon who are convicted of crimes that carry a sentence of one year or more serve their sentence in the State prison system. People with shorter sentences go to local county jails. The Oregon Department of Corrections (ODOC) manages the female side of the State prison system with a 662-bed minimum security facility and a 713-bed medium security facility for women. These two centers for women, collectively called the Coffee Creek Correctional Facility (CCCF), are co-located in Wilsonville, about 30 min south of Portland, Oregon. The Religious and Victim Services Unit together with the Volunteer Programs Unit in the ODOC organize a diverse range of humanist, spiritual and religious services that women at CCCF can choose to attend. 
Oregon organizes its prison chaplaincy system differently to many other US and International prison systems. Many prison systems, for example, use unpaid volunteer chaplains, have very few chaplains for the amount of people in prison, or tend to have chaplains that represent only the dominant faith of the state or country. The Oregon Department of Corrections hires enough full-time professional chaplains who are relatively well paid, and have the capacity to reach the entire inmate population. Chaplains in other U.S. state prison systems are often recruited and supervised by the individual prison at which they work and belong to the chain of command within that prison. In Oregon, the chaplains serve under the Religious and Victim Services Unit which is part of a centralized Offender Management and Rehabilitation Division that has responsibility for overseeing the intake, education, training, treatment, health, HSR, victim, volunteer and reentry services for the prison system. The chaplains answer, therefore, to their own centrally-based Administrator/Head Chaplain who sets the direction for the chaplaincy work in all 14 of the state prisons housing about 14,800 men and women, and oversees the budget, goals, policies, practices, hiring, training and supervision of the unit staff. ${ }^{1}$ This administrative structure relieves the chaplains from having to work within a chain of command that is primarily concerned with maintaining safety and security, and allows them to focus on their unique roles such as: (1) ameliorating the dehumanizing tendencies of the US penal system and cultural attitudes toward prisoners; (2) supporting and challenging staff to grow in their humanity and professional skills; (3) selecting, training, coaching and organizing volunteers and HSR opportunities; and 4) fostering a context that maintains and encourages the inmates to develop their meaning-making, humanity, pro-social skills/support, and positive ways of contributing to the community.

The ODOC vision is that each chaplain, regardless of his or her own humanist, spiritual or religious tradition serves the HSR needs of every woman or man in prison. Thus, while an Oregon prison chaplain may be a minister, imam, rabbi, priest, pastor or leader in their own humanist, spiritual or religious tradition, his or her function is not to advance their own tradition but to support and develop each prisoner's pro-social skills/support and unique history and narrative of meaning-making in life. The chaplain's primary job is to protect, ensure and advance the constitutional and legal rights and responsibilities of the women and men in prison to express, practice and grow in their way of making meaning whatever that path might be ( $\mathrm{O}^{\prime} \mathrm{Connor}$ et al. 2006). The staff members in the Religious and Victim Services Unit in the Oregon prison system have come from many different backgrounds over the years including: Native American, Zen Buddhism, Sunni Muslim, Presbyterian, Jewish, Unitarian/Universalist, Baptist, Foursquare Christian, Lutheran, Shambhala Buddhism, Latter-day Saints, Humanist, Methodist, Missouri Synod Lutheran, Catholic etc. The Oregon model of prison chaplaincy has been featured in an award winning documentary film called CHAPLAINS made by Martin Doblmeier and Journey Films that aired recently on PBS stations across the country (Doblmeier 2015). The model has also been discussed on National Public Radio in a program produced by Interfaith Voices, called Lowering Recidivism Through Spiritual Care (Morris 2017).

In 2004, Congress passed a federal law called the Religious Land Use and Institutionalized Persons Act (RLUIPA) to prevent its finding that "persons residing in institutions are sometimes subject to discriminatory or arbitrary denial of the ability to practice their faiths beyond what is needed for the security and proper functioning of the institution" from continuing. RLUIPA has dramatically reduced the ability of prison and jail administrations to restrict the practice of humanist, spiritual and religious expression because of security or practical concerns. Just as prisons and jails must provide inmates with health care, they must now provide inmates freedom to express and practice their belief and meaning systems, unless there is a compelling government reason to prevent such expression and practice. The Supreme Court has consistently ruled that people do not lose their First Amendment

1 Tom O'Connor, one of the authors on this paper, held the Administrator of Religious and Victim Services position with the Oregon Department of Corrections from 2000 to 2008. 
constitutional rights to practice their religion, spirituality, or way of life, when they are incarcerated. Before RLUIPA, prisons had fairly wide scope as to what they would and would not accommodate, but now they must approximate to the standards of expression that are found in the community ( $\mathrm{O}^{\prime} \mathrm{C}$ onnor et al. 2006). These First Amendment rights and responsibilities within prison contexts extend beyond spirituality and religion into humanism. In 2005, the US Court of Appeal held that atheism was afforded the same protection as religion under the First Amendment, and ordered a prison in Wisconsin to allow an inmate to form a study group for atheists alongside the religious study groups they already allowed (Kaufman vs. McCaughtry 2005).

The Oregon chaplains would not be able to meet the diverse and widespread HSR needs of the 14,800 men and women in prison without the help of a substantial cadre of over 2000 volunteers (O'Connor and Bogue 2010). The Oregon prison system has deliberately chosen to invest in supporting and developing these volunteers, and facilitating their work. Alongside the Religious and Victim Services Unit the department has a Volunteer Programs Unit that is likewise centrally based with its own Administrator. Approximately $75 \%$ of the volunteers work directly with the Religious and Victim Services Unit, and the two units work very closely with each other. The majority of the services and events organized by the chaplains and volunteers are religious or spiritual in nature, however, the chaplains and volunteers are increasingly involved in facilitating services that take place in a humanist or secular context, without any religious or spiritual content, such as non-violent communication classes, social study groups, victim-offender dialogues, restorative justice programs, third level educational programs, parenting, and secular meditation such as Transcendental Meditation (Nidich et al. 2016). Chaplains also do a great deal of one-on-one counseling, informal interaction, and death/grief work with the men and women in prison (Sundt and Cullen 1998, 2002). In 2011, $\mathrm{O}^{\prime}$ Connor et al. sent a survey to 2217 volunteers listed in the ODOC's internal volunteer database and $401(18 \%)$ responded. Interestingly, $47 \%$ percent of those who responded said they primarily considered themselves to be "a religious volunteer", $32 \%$ said they primarily considered themselves to be "a spiritual volunteer" and 22\% said "a secular or humanist volunteer" (O'Connor et al. 2011). It should be noted that the HSR demographics of people who live in Oregon are different to many other parts of the US. For example, 77\% of people in Alabama and Mississippi say they are "highly religious" compared to $64 \%$ in Utah, $47 \%$ in Oregon, and 33\% in Maine. Fifty-three percent of people in Utah say they attend worship services at least weekly, compared to 39\% in North Carolina, 29\% in Oregon and 21\% in Vermont (Pew Research Center 2014). Oregon has a very diverse set of religious traditions and it has a growing rate of people who consider themselves spiritual without belonging to a particular denomination (Oregon Values and Beliefs Project, 2013).

There are currently 21 full-time chaplains, one full-time victim services coordinator, and five full-time administrative staff in the Religious and Victim Services Unit, and three full-time staff in the Volunteer Program Unit. These 30 staff serve 14 prisons and approximately 14,800 prisoners with an annual budget of $\$ 3.7$ million (\$3.4 million for the Religious and Victim Services Unit and $\$ 0.2$ million and the Volunteer Programs Unit). The word, "volunteer," comes from the Hebrew language and means, "to willingly give" (Cnaan and Amrofell 1994). Giving willingly is an apt description of the prison volunteers because the 2011 study of the Oregon volunteers estimated they give about 404,199 $\mathrm{h}$ of service each year. On average, the volunteers said they gave about nine hours of service and six hours of prep time each month to their prison or reentry work. This amounts to a $\$ 9.7$ million contribution to the department each year using the Independent Sector's 2016 figure of $\$ 24.14$ for the value of a volunteer hour (Independent Sector 2016). If staff were to provide an equal number of service hours the department would have to hire 194 full-time staff at a cost of well over $\$ 13$ million. The volunteers also report driving an estimated 5 million miles each year to do their volunteer work at their own cost ( $\mathrm{O}^{\prime}$ Connor et al. 2011). So Oregon's prison chaplains and volunteers provide a great deal of "programming" at very lost cost to the department and the community.

To better understand this programming we used the ODOC computerized program signup and attendance system to track the HSR engagement of all women $(N=349)$ and men $(N=3009)$ who 
entered the Oregon prison system in 2004 and served at least one year of incarceration. Mirroring gender-specific patterns of HSR involvement that are found in the community (Stark 2002; Pew Forum on Religion and Public Life 2008), women in prison were much more likely to attend HSR events than men. However, both the women and men attended at very high rates. Ninety-five percent of the women and $71 \%$ of the men voluntarily attended at least one HSR event during their first year in prison. On average $58 \%$ of the total female population and $33 \%$ of the total male population attended HSR services each month during their first year in prison ( $\mathrm{O}^{\prime}$ Connor and Duncan 2011). This surprisingly high level of engagement is consistent with a national survey which found that religious programming was the single most common form of programming in US state prisons (Beck et al. 1993).

There were several other significant differences between the HSR engagement of women and men. For example, females $(70 \%)$ were equally likely as males $(68 \%)$ to have attended spiritual or religious services as a child, but women $(23 \%)$ dropped below the rates for males $(30 \%)$ as a teenager, and then the women rose $(66 \%)$ to higher levels than men (54\%) after they were arrested. Compared to the men, the women were less likely to have a sexual offence or to be a gang member, and they had lower levels of risk of recidivism. Women were also more likely to cross over and attend a wider variety of events organized by the different humanist, spiritual and religious traditions. Six factors predicted total number of HSR attendances by men - prior theft, type of crime (person, property, statutory), a current or prior sex offence, older age, spiritual assessment, and Hispanic ethnicity-but there were no discrete factors predicting attendance by women ( $\mathrm{O}^{\prime} \mathrm{Connor}$ and Duncan 2011). Indeed the patterns of involvement for the men and women were so different that we decided we needed separate follow-up studies to properly understand this gender-specific HSR involvement in prison and its impact on post-prison success.

\section{Theory and Research}

In our judgement, the research on how or whether humanist, spiritual and religious engagement in a correctional environment might contribute to desistance (the evolving self-narrative and journey whereby one lifts oneself out of crime and into a pro-social life free of crime) is promising but inconclusive. The most methodologically rigorous review of the research is a meta-analysis conducted by the Washington State Institute for Public Policy (WSIPP) in 2006. While a little dated now, the WSIPP study is still probably the best bedrock to stand on due to its rigor. WSIPP found 291 studies on the impact of correctional programs on recidivism that met its methodological criteria, and these included six "faith-based" or "faith-informed" studies. Only two of the six studies found a positive effect on recidivism; one of which (Wilson et al. 2005) studied a later more-developed version of a faith-based transitional program in Detroit that was included in the four studies that failed to find an impact (O'Connor et al. 1997). The other study that found a positive effect was the study with the highest effect size $(-0.388)$ for reducing recidivism across all of the 291 evaluations (Wilson et al. 2005). WSIPP's failure to find overall statistical significance for the six studies led it to conclude that the research in this program area was "inconclusive" and "in need of additional research and development" (Aos et al. 2006).

Johnson's review of the broad literature on religion and delinquency/crime is helpful because it examines a variety of ways of measuring religion and outcomes related to crime, and includes a large number (272) of studies but of varying methodological rigor. Johnson's conclusion is that "clear and compelling empirical evidence exists that religiosity is linked to reductions in crime" (Johnson 2011). Dodson et al. (2011) also review some of the literature and conclude that "faith-based programs "work" to reduce recidivism." Several studies, however, have failed to find a link between religious and spiritual support and reductions in recidivism (Burnside et al. 2001; Johnson 2004; Trusty and Eisenberg 2003; O'Connor et al. 1997). Other studies have found less direct and more nuanced links. For example, a study using data from the Serious and Violent Offender Reentry Initiative found that religious and spiritual support did not significantly relate to criminal reoffending, although the study did find that such support had a strong and robust effect on the likelihood of desisting from substance 
use for ex-offenders who had a low risk of recidivism (Stansfield et al. 2017). A second study using data from the Serious and Violent Offender Reentry Initiative found that a person's baseline of religious support did not protect against substance use or reoffending post-release. A person's increase in religious support from the baseline did protect against substance use post-release, but not against reoffending. The interaction, however, between baseline and increase in support was significantly related to lower levels of offending post-release (Mowen et al. 2017).

Several studies have found that the spiritual and religious practices of male and female prisoners help them to have less prison infractions and adjust in a psychologically healthy way to prison life, manage guilt, and find motivation, direction, peace of mind, and meaning in life, as well as hope for the future and support to make a shift in their lifestyle and behaviors (Clear et al. 1992; Clear and Sumter 2002; Dammer 1992, 2002). O'Connor et al. found that participation in the Transition of Prisoners (TOP) program for men, originally created by Prison Fellowship, significantly reduced the number of walk-aways and escapes from a pre-release prison in Detroit (O'Connor et al. 1997). O'Connor and Perreyclear found that religious participation in a South Carolina prison for men reduced in-prison infractions ( $\mathrm{O}^{\prime}$ Connor and Perreyclear 2002).

A study of 214 women in prison found that the women who received significant support from religion had better adjustment to prison, and less depression and prison infractions (Levitt and Loper 2009). Dye and colleagues (Dye et al. 2014) found that more frequent religious engagement among a group of women serving life sentences was associated with better prison adjustment, largely through helping women deal with depression. Two Federal Bureau of Prisons studies explored the reasons why female and male inmates participated in a multi-faith prison program (Camp et al. 2006) and found that this participation reduced in-prison infractions (Camp 2008). A longitudinal study by Giordano et al. (2008) studied the influence of spirituality as measured by feelings of being close to God and religious participation on the life-course patterns of crime for 152 people, $51 \%$ female and $49 \%$ male. Controlling for traditional predictors of desistance they concluded that "although the longitudinal results do not show significant main effects on life-course patterns of crime for the sample as a whole, the in-depth life-history data do document positive effects of religion and spirituality for some individuals and under some conditions (Giordano et al. 2008)." These studies reveal a potentially important role for HSR practices for women in prison, especially given the high incidence of depression and other mental health problems faced by female inmates (Kruttschnitt et al. 2000), and how female inmates benefit particularly from positive relationships and social support (Severance 2005).

A study that links meaning-making and social support comes from the Minnesota Department of Corrections. This study found that the InnerChange Freedom Initiative (IFI), a faith-based prisoner reentry program, significantly reduced reoffending in a sample of 732 offenders who had participated in the program and were released from Minnesota prisons between 2003 and 2009 (Duwe and King 2013). Importantly its authors qualify the meaning of their results by say the findings "suggest that the beneficial recidivism outcomes for IFI participants may have been due, in part, to the continuum of mentoring support some offenders received in the institution and the community. The results imply that faith-based correctional programs can reduce recidivism, but only if they apply evidence-based practices that focus on providing a behavioral intervention within a therapeutic community, addressing the criminogenic needs of participants and delivering a continuum of care from the institution to the community. Given that IFI relies heavily on volunteers and program costs are privately funded, the program exacts no additional costs to the State of Minnesota. Yet, because IFI lowers recidivism, which includes reduced reincarceration and victimization costs, the program may be especially advantageous from a cost-benefit perspective."

Another study of 16,420 people released from Minnesota prisons between 2003 and 2007 found that prison visits from siblings, in-laws, fathers, and clergy significantly reduced recidivism. The authors of the study recommended that prisons and jails become more "visitor friendly" and made the following important but simple point: "considering the impact of visits from clergy and, to a lesser extent, mentors 
appear to have on reoffending, it may be beneficial for visitation programs to focus on facilitating visits from clergy, mentors, and other volunteers from the community (Duwe and Clark 2011). Since 2000, the Oregon prison system has been consciously and progressively making its prisons more visitor, clergy and volunteer/mentor friendly. The Duwe study on visitation (Duwe and Clark 2011) and other studies (Bales and Mears 2008; Mitchell et al. 2016) that have found a social tie/visitation effect gives us a clear hint that the HSR effect, if there is one, is connected in some way to power of increased social support. Meaning-making is an inherently social endeavor.

Germaine to this literature are important findings from a series of meta-analytic studies commissioned by the American Psychological Association (APA) (Norcross and Wampold 2011). These studies examined the outcomes from adapting psychotherapy to eight different patient characteristics one of which was the religious and spiritual $(\mathrm{R} / \mathrm{S})$ outlook or approach of patients. In the parlance of the Risk, Need and Responsivity model of reducing recidivism, these studies were examining the Responsivity principle. The meta-analyses categorized these R/S outlooks into four different types of spirituality based on the type of object a person feels a sense of closeness or connection to: (1) humanistic spirituality; (2) nature spirituality; (3) cosmic spirituality; and (4) religious spirituality (Worthington et al. 2011). Many humanists, secularists and atheists etc., however, do not like to use word "spiritual" to describe their perspective on life, so we prefer to collapse this fourfold categorization into the threefold classification we have been using in this paper based on a person's way of making ultimate meaning in the world and their affective connection to the world and the transcendent: humanist; spiritual (both nature and cosmic spirituality); and religious. This set of 8 meta-analytic studies found that four out of the eight patient factors, including HSR, were "demonstratively effective" and are thus considered to be evidence-based practices by the APA. When therapists brought their patient's unique and individual ways of making ultimate meaning into therapy, the patients had better psychological outcomes and they also had improved outcomes around meaning. It therefore behooves Corrections Departments in the context of programming to take note that the APA has recommended, as an evidence-based practice in psychology, that all psychologists and counselors integrate humanism, spirituality, and religion into their work in a way that matches each client's particular way of establishing ultimate meaning in life or feeling connected to something that is vitally important in their lives (Norcross and Wampold 2011; Worthington et al. 2011). In summary, HSR engagement cannot yet be considered as an "evidence-based practice" for helping people to better adjust to prison live and be more successful in the community after prison, but it certainly should be viewed as an encouraging practice that has good evidence to suggest its cost-effectiveness.

\section{Data and Methods}

The current study relies on data from the 349 women who entered the Oregon prison system during 2004 and who served at least one full year in prison. In 2017, we returned to the cohort of women who entered the prison system in 2004 and collected data on any rearrests and reconvictions since their release from prison. Of the original 349 women in our sample, 339 were eventually released from prison and spent at least one-year post-incarceration in the community, before we collected follow-up data. The 339 thus formed the sample for our analysis.

\section{Dependent Variable}

Recidivism: Given that our study sample exited prison at varying times from 2005 onwards, we used two different measures of recidivism to account for the significant variations in 'time at risk' (i.e., back in the community). Our first assesses whether an individual was rearrested for a new personal, property or statutory offense within their first 12 months after release. This method examined re-arrest within one year as a binary outcome $(1=$ yes, $0=$ no $)$.

Our second method follows recommendations by other researchers in this field (Duwe and Clark 2017; Stansfield and Williams 2014) to account for varying exposures to the risk for recidivism. We do so by examining any recidivism event over the entire 13-year follow up period for each person. For this we 
use a Cox Regression technique to measure both the timing and likelihood of recidivism, using the number of days to a new arrest as time to (first) failure. There are well known limitations to using rearrests as a measure of recidivism (LoBuglio and Lymann 2006), including that rearrests can capture charges that are later dropped or changed, and that a person can be acquitted. Nevertheless, the use of official data on rearrests is methodologically consistent with many prior studies of recidivism. Furthermore, measures of reconviction or re-incarceration in Oregon would undercount reoffending behavior, given that technical violations are handled at the local county level.

HSR Attendance: A prior study found a significantly higher proportion of women begin their HSR participation earlier than men and maintain higher levels of attendance throughout their first year of incarceration ( $\mathrm{O}^{\prime}$ Connor and Duncan 2011). Given that $95 \%$ of women in prison attended at least one HSR event during their first year in prison, we wanted to capture the variation in extent of attendance. In the current study, participation in HSR programming was measured via the average monthly attendance of women, calculated by summing the total hours of attendance and dividing by the total number of months served. This ranged from a low of $0 \mathrm{~h}$, to a high of $28 \mathrm{~h}$ per month. Eighty percent of the sample had 4 or less hours per month. We created a categorical variable indicating whether women attended on average less than one HSR hour per month $=1$, up to two hours per month $=2$, up to three per month $=3$, up to four per month $=4$, or four or more per month $=5$.

Other Programs and Work: To adequately examine the relationship between HSR attendance and recidivism independent of participation in other rehabilitation programs, we also controlled for participation in the following most commonly attended programs: substance treatment, cognitive programming, job skills or on the job training/work, and education. We used a count measure where 1 point was ascribed for each additional program attended to assess participation in other programming.

Assessed Risk: The validated risk measure used to assess the risk of recidivism for an Oregon inmate is the Automated Criminal Risk Score or ACRS (Oregon Department of Corrections 2015). The department calculates the ACRS automatically by scoring 7 factors: age, earned time, sentence length, prior revocation, number of prior incarcerations, prior theft convictions, and the current offense severity (ODOC, 2009). The formula for calculating ACRS risk for women and men is slightly different, but the factors are the same. In the context of this study it is also important to note that the ACRS includes age as a factor and so it changes over time. We could have included a separate control measure for age at release, but for reasons of multicollinearity we decided not to do so and control for age via its inclusion in ACRS. Age is a very important control variable because it is so strongly related to recidivism, and the ACRS controls for this. We used the ACRS score for the women at the time of their release. The continuous ACRS is measured on a scale of 0 to 1 , with higher scores indicating higher assessed risk. Assessed risk was included as a control measure to determine whether any relationship between HSR attendance and recidivism was sustained for all levels of risk, providing a more rigorous test of the impact of HSR.

We also used three variables that may be indicative of risk that are not captured in the risk measure. This includes whether the person was sanctioned for a minor disciplinary infraction at any point during their entire prison stay $(1=$ yes), whether a person was sanctioned for an assault or major disciplinary infraction while in prison during their entire stay $(1=$ yes), and the total amount of time served in the Oregon DOC prior to release (measured in years).

Demographic Variables: We controlled for ethnicity (non-Hispanic white $=1$, ethnic minority $=0$ ). Given the demographic make-up of Oregon, further disaggregation of racial and ethnic groups was not possible because of low cell counts.

Spiritual Assessment: A subset of our sample voluntarily filled out a spiritual and religious assessment offered to them by the Religious and Victim Services Unit during their prison intake process. The spiritual and religious assessment explored various aspects of the person's background and current practice such as their spiritual and religious orientation, upbringing, and spiritual and religious behavioral patterns prior to incarceration. The survey included the Age-universal Religious Orientation Scale (Gorsuch and Venable 1983) \{Griffin, 1987 \#19809) which measures two independent 
dimensions of a person's religiosity, intrinsic and extrinsic orientation. Nine of the scale's 20 items (scored on a 5-point Likert Scale, ranging from 1 indicating strong disagreement to 5 indicating strong agreement) pertain to intrinsic orientation, including: "I enjoy reading about my religion", "It is important to me to spend time in private thought and prayer", and "I would rather join a Bible study group than a church social group." Eleven items pertain to extrinsic orientation including, "I go to church because it helps me make friends", "Although I am religious, I don't let it affect my daily life", and "I go to church mainly because I enjoy seeing people I know there." The score on each subscale is obtained by summing the scores of the 9 or 11 items, providing a range of 11 to 55 for extrinsic orientation and 9 to 45 for intrinsic orientation. In addition to including the religious orientation scores in our analyses, we included whether or not a person was from a religious family (no $=0$, yes $=1$ ), and their recent religious behavior measured via the question: In the past 6 months, have you listened to religious programs on the TV or radio? Respondents could select never $=1$, sometimes $=2$, and often $=3$.

\section{Results}

Table 1 displays the descriptive characteristics of our sample of 339 women, and the subset of 120 women who completed the spiritual assessment at intake. Almost $63 \%$ of the women in our sample had at least one re-arrest by 25 August 2017, the date we collected the recidivism data. Just over $22 \%$ of the women were re-arrested during their first year back in the community. As previously reported, upwards of $94 \%$ of women in the Oregon prison system attended at least one HSR program during their first-year prison, and Table 1 shows that the women in our sample had an average of $3 \mathrm{~h}$ per month. Interestingly, attendance level is not significantly affected by risk level. Prior studies of males in prison have found that higher risk men were significantly less likely to have HSR involvement in prison \{O'Connor, $2011 \# 19801\}$ (Stansfield et al. 2017). Our data revealed that women in the low, medium, and high risk of recidivism categories all had an average of just over 3 HSR hours of attendance per month.

Table 1. Descriptive Characteristics for Sample.

\begin{tabular}{lcccc}
\hline & Mean & Std. Dev. & Min & Max \\
\hline Full Sample $(\boldsymbol{n}=\mathbf{3 3 9 )}$ & & & & \\
Any Re-arrest & 0.626 & 0.484 & 0 & 1 \\
Any Re-arrest in 1 Year & 0.224 & 0.417 & 0 & 1 \\
Days to Re-arrest (Total Period) & 1100.578 & 1220.751 & 3 & 3989 \\
Days to Re-arrest (1 year) & 159.90 & 98.91 & 3 & 364 \\
\hline Avg. Monthly HSR Hours & 2.802 & 1.558 & 1 & 5 \\
Total Time Served (years) & 2.308 & 1.924 & 1 & 11.8 \\
Assessed Risk & 0.218 & 0.180 & 0 & 0.626 \\
\hline Ethnicity (White = 1) & 0.861 & 0.346 & 0 & 1 \\
Other Needs Programs & 3.209 & 1.015 & 0 & 5 \\
$\quad$ Any Education Hours & 0.851 & 0.357 & 0 & 1 \\
$\quad$ Any Substance Treatment & 0.560 & 0.497 & 0 & 1 \\
$\quad$ Any Cognitive Therapy & 0.632 & 0.483 & 0 & 1 \\
$\quad$ Any Job Hours & 0.882 & 0.130 & 0 & 1 \\
Minor Sanction in Prison & 0.330 & 0.471 & 0 & 1 \\
Major Sanction in Prison & 0.459 & 0.499 & 0 & 1 \\
\hline Spiritual Assessment $(n=\mathbf{1 2 0})$ & & & & 4 \\
Intrinsic Score & 34.042 & 6.132 & 11 & 45 \\
Extrinsic Score & 27.575 & 6.175 & 14 & 51 \\
Religious Family & 1.366 & 0.484 & 1 & 2 \\
Religious Behavior & 1.573 & 0.699 & 1 & 3 \\
\hline
\end{tabular}

+ Less than $1 \mathrm{~h}$ of attendance per month $=1$; up to $2 \mathrm{~h}$ of attendance per month $=2$; up to 3 per month $=3$; up to $4=4$; more than $4=5$.

Our first analysis revisits the findings of O'Connor and Duncan (2011), as we explore what we can learn about the women who have higher HSR attendance using the subset of 120 women who voluntarily took a spiritual assessment at intake. Table 2 presents the results of an ordered 
logistic regression estimating levels of monthly attendance at HSR services. Intrinsic religiosity was significantly and positively associated with average monthly attendance. The Odds Ratio indicates that for a one unit increase in intrinsic religious orientation, the odds of four or more hours of attendance per week versus the combined lower levels of attendance are 1.1 times greater, given the other variables remain constant. This suggests that women in the Oregon system with higher levels of attendance are attending for largely internal, meaning-driven reasons. This finding is consistent with reports of why men attend HSR services in Oregon ( $\mathrm{O}^{\prime}$ Connor and Duncan 2011), and supported by more recent work exploring why women turn to faith during treatment for drug addiction in a halfway house (Kerley et al. 2014).

Table 2. Ordered Logistic Regression Model of Women's Average Monthly HSR Attendance.

\begin{tabular}{|c|c|c|c|}
\hline & OR & SE & $p>\mathrm{z}$ \\
\hline Intrinsic & $1.105^{* *}$ & 0.039 & 0.005 \\
\hline Extrinsic & 0.986 & 0.034 & 0.689 \\
\hline Religious Family & 0.737 & 0.278 & 0.418 \\
\hline Religious Behavior & $3.032 * * *$ & 0.911 & 0.000 \\
\hline Assessed Risk & 0.215 & 0.230 & 0.150 \\
\hline White & $0.187^{* *}$ & 0.115 & 0.006 \\
\hline \multicolumn{4}{|l|}{ Needs Programs: } \\
\hline Education & $3.245^{*}$ & 1.861 & 0.040 \\
\hline Substance & 1.569 & 0.626 & 0.259 \\
\hline Cognitive & $2.777 *$ & 1.100 & 0.010 \\
\hline Job & 0.528 & 0.867 & 0.697 \\
\hline$x^{2}$ & 51.450 & & \\
\hline $\mathrm{R}^{2}$ & 0.147 & & \\
\hline Log Likelihood & -149.440 & & \\
\hline
\end{tabular}

Relatedly, recent religious behaviors prior to prison were also associated with higher HSR attendance. For a one-unit change in the amount women listened to religious programs on the radio or television in the six months prior to custody, the odds of a higher level of attendance versus lower levels of attendance are almost 3 times greater. Importantly, the number of other programs that the women participated in was also significantly associated with HSR attendance. This is an important finding for at least two reasons. First, it suggests that there is some overlap reflective of a higher motivation to seek change. Secondly, it suggests that future studies seeking to estimate the effect of HSR programs in prison on recidivism must be able to account for other rehabilitation programs, so as to measure how much HSR programming may actually support or enhance the impact of participation in other rehabilitation programs.

Table 3, Model 1 presents the results of our logistic regression model estimating the likelihood of re-arrest within the first-year post-release, as a function of our independent variables. We find that the average monthly attendance at HSR services was moderately associated with lower recidivism. This association is significant while controlling for the total number of other programs attended by women in the sample, demonstrating that HSR attendance may be associated with further reductions in recidivism above and beyond participation in other prison rehabilitation programs such as education, work and cognitive programming, and independent of risk of recidivism level. Consistent with prior research on prison experiences and recidivism, we also found that both minor and major sanctions in prison were associated with a higher likelihood of recidivism perhaps indicating that self-control or self-regulation skills are an important factor in reducing recidivism.

Because women in our sample exhibited a wide range in average monthly HSR attendance, we explored whether there is a threshold that must be met before recidivism benefits are conferred. Model 2 shows the results of a logistic regression model, that now include each category of HSR attendance. The odds of recidivism were significantly lower for the $20 \%$ of women with four or more hours of 
attendance each month compared to women with less than one hour per month. This suggests that establishing a more regular pattern of attendance and participation may be important to incur the benefits of prosocial support and possibly a sign of higher motivation to seek change. This finding is consistent with most behavior change models, which stress that dosage and consistency of engagement, regardless of program type, are important factors for success.

Table 3. Logistic Regression Estimating the Relationship between HSR Attendance and Re-arrest within 1 year of Release $(N=339)$.

\begin{tabular}{|c|c|c|c|c|c|c|}
\hline & OR & SE & $p>\mathrm{z}$ & OR & SE & $p>\mathrm{z}$ \\
\hline Monthly HSR & $0.738^{* *}$ & 0.071 & 0.002 & & & \\
\hline Up to 2 & & & & 1.273 & 0.457 & 0.501 \\
\hline Up to 3 & & & & 0.905 & 0.390 & 0.817 \\
\hline $\mathrm{Up}$ to 4 & & & & 0.599 & 0.307 & 0.317 \\
\hline 4 or more & & & & $0.272 * *$ & 0.125 & 0.005 \\
\hline Time Served & $0.762^{* *}$ & 0.079 & 0.008 & $0.771 *$ & 0.080 & 0.012 \\
\hline Assessed Risk & 1.039 & 0.805 & 0.96 & 1.003 & 0.791 & 0.997 \\
\hline White & 1.189 & 0.490 & 0.674 & 1.233 & 0.519 & 0.619 \\
\hline Education & 0.999 & 0.387 & 0.999 & 0.975 & 0.378 & 0.948 \\
\hline Substance & $0.557^{*}$ & 0.158 & 0.039 & 0.548 * & 0.157 & 0.036 \\
\hline Cognitive & $1.981 *$ & 0.627 & 0.031 & $1.988 *$ & 0.636 & 0.032 \\
\hline Job & 1.135 & 1.342 & 0.915 & 1.102 & 1.340 & 0.936 \\
\hline Minor Infraction & 1.973 * & 0.590 & 0.023 & $1.965 *$ & 0.592 & 0.025 \\
\hline Major Infraction & $2.031 *$ & 0.616 & 0.019 & $1.953 *$ & 0.603 & 0.030 \\
\hline Constant & 0.427 & 0.516 & 0.482 & 0.253 & 0.313 & 0.266 \\
\hline$x^{2}$ & 39.080 & & & 42.90 & & \\
\hline Log Likelihood & -163.569 & & & -161.662 & & \\
\hline
\end{tabular}

Finally, we conducted a survival analysis to assess the rate of reoffending across our entire follow-up period to account for different periods at risk of reoffending among our sample. Survival analysis was particularly useful given that the women in the study entered the 'at-risk' period (i.e., released from prison) at different points in time and could be censored at any point over the 13-year study period. Survival analysis correctly accounts for censored cases in estimating the probability of recidivism, while allowing for the likelihood that more than half the women in the sample will never reoffend. Estimation of Cox proportional hazards models helped us to relate time to "failure" to covariates associated with that time as displayed in Table 4 . The results again confirm that a higher level of HSR attendance is moderately associated with a reduction in reoffending. Furthermore, minor and major sanctions in prison were positively associated with the rate of re-arrest while a longer time served in prison was associated with a lower rate of re-arrest. 
Table 4. Cox Regression Estimating the Relationship between HSR Attendance and the Rate of Re-arrest Across 14 Years $(N=339)$.

\begin{tabular}{|c|c|c|c|}
\hline & HR & SE & $p>\mathrm{z}$ \\
\hline Monthly HSR & $0.773^{* *}$ & 0.063 & 0.001 \\
\hline Time Served & $0.786^{*}$ & 0.074 & 0.010 \\
\hline Assessed Risk & 1.008 & 0.648 & 0.990 \\
\hline White & 1.014 & 0.343 & 0.968 \\
\hline Education & 0.891 & 0.275 & 0.709 \\
\hline Substance & $0.566^{*}$ & 0.133 & 0.015 \\
\hline Cognitive & $1.728 *$ & 0.465 & 0.042 \\
\hline Job & 1.269 & 1.324 & 0.819 \\
\hline Minor Infraction & $1.780 *$ & 0.425 & 0.016 \\
\hline Major Infraction & $1.916^{* *}$ & 0.475 & 0.009 \\
\hline$x^{2}$ & 40.710 & & \\
\hline Log Likelihood & -424.76 & & \\
\hline
\end{tabular}

\section{Discussion}

In this paper, we describe in some detail how prison chaplains and volunteers in Oregon are able, at low cost, to provide a great deal of humanist, spiritual and religious programming that reaches almost the entire female population in the prison system. This Oregon HSR model helps the incarcerated women to make new meaning and find support in their lives from pro-social citizens in a way that is congruent with the criminogenic principle of Responsivity, evidence-based practices in psychology, and the Constitution's first amendment prohibition on the establishment or prevention of religious exercise.

For a variety of reasons, that we were not able to fully determine, some women in prison self-select to attend these HSR services at increasingly higher levels, but we did find evidence to suggest that part of this self-selection process is driven by greater levels of an intrinsic desire and motivation to make meaning. We discovered that these higher levels of HSR dosage and intensity have a significant impact on both short-term (one year) and long-term (13 year) post-prison recidivism controlling for a wide range of factors including risk of recidivism (incorporating age), other in-prison program involvement, ethnicity, length of stay and in-prison infractions. We were unable to measure change in, or levels of post-prison involvement in HSR practices and future studies would benefit from the addition of such data. Previous studies have shown that the prison chaplains and volunteers, who build these HSR relationships with the women, have a great deal of pro-social, spiritual, and human capital to share with the women and the women have a great deal to share with the chaplains and volunteers. Presumably this capital and support "rubs off" on the women and the chaplains/volunteers. The chaplains and volunteers are deeply connected to and embedded in the all of the major social institutions of family, education, work, law, democracy (voting), community, and HSR meaning-making. The chaplains and volunteers model how to live with pro-social attitudes, beliefs and values, with pro-social friends and support, with satisfying work and intimate relationships, and without substance abuse and traumatic inducing behaviors such as poor communication and violence. In contrast to the rejection and condemnation narratives that are at least partially inherent in the culture of the US justice and prison systems, the chaplains and volunteers represent a narrative of restoration, redemption and belonging that is available to the women despite their past failures. Informally therefore, the chaplains and volunteers, create an environment or context that directly counters the many criminogenic risks and needs that are present in the herstories of the women. Context conditions consciousness and sufficient exposure or engagement with this enabling context encourages new identities and skills of pro-social agency to emerge.

It is our hypothesis that the context we are describing allows new meaning to develop that is unique to each woman and strengthens their motivation, social support and self-regulation skills. 
These three factors-motivation, social support, and self-control/regulation—are crucial to human development and desistance from crime. The constructivist developmental model of Robert Kegan posits three major levels or stages of human achievement and complexity: (1) the socialized mind; (2) the self-authoring mind; and (3) the self-transforming mind (Kegan 1998). Many of the adults who end up in prison have not yet achieved the level of development that is represented by the socialized mind; their level of development is a sovereign mind where their needs and desires dominate and they are incapable of thinking abstractly and thus see things in concrete or black and white terms. This black or white way of constructing the world is cute in children but deeply problematic in adults who are frozen at this stage of development. People who attain to the level of the socialized mind are now able to think abstractly and can see things from the perspective of others and the needs of others. At this socialized stage people are "on the bus", they realize they are part of society and can work collaboratively with others to construct a meaningful life. After some time of being "on the bus" people develop further and they are ready, when they develop a "self-authoring mind" to "drive the bus". This more developed and complex way of constructing meaning involves a far greater degree of agency, leadership and internal decision-making capacity than the self-authoring mind. Studies have shown that about $13 \%$ of adults have a pre-socialized mind, $14 \%$ have a socialized mind, $32 \%$ are in between a socialized and self-authoring $\operatorname{mind}, 34 \%$ have a self-authoring mind, $6 \%$ are on the way to having a self-transforming mind, and only $1 \%$ have a self-transforming mind. In our experience almost all of the chaplains and volunteers have attained at least the level of the socialized mind and many are on their way to or at the level of a self-authoring mind. This means they able to assist many of the women in prison who may be stuck at the pre-socialized level of development to "get on the bus" and a few of them who are ready to start "driving the bus"

The main focus of our study is at a personal or individual level, as it concerns the relationship between the women in prison and their HSR behavior. As such the study does not specifically examine the influence on crime and desistance patterns of the broader situational, collective, and sociological structures such as the overrepresentation of minorities and the impact of class on incarceration; or the amount of trauma, sexual abuse and violence in the lives of women who are incarcerated. We understand that this narrower individual focus is a limitation of our study that cannot be overcome within the confines of its methodology. Furthermore, our question about whether or not the provision of and engagement with HSR services at $X$ cost leads to individual desistance from crime tends to bestow an instrumental or "I-it" feel to the complex web of human relationships, engagements and meaning-making that we are trying to understand. Our argument is not that the purpose of developing HSR in prison is to reduce recidivism, as this would reduce HSR to a state instrument of social control that is used "on" the women in prison. Rather, our hope was to show that the co-creative process of diverse meaning-making engaged in by women prisoners, volunteers and state-paid chaplains that is protected by the US constitution is something good in and of itself, and that it also assists the women to advance in their journey of desistance. The main focus of our study is at a personal or individual level, as it concerns the relationship between the women in prison and their HSR behavior. As such the study does not specifically examine the influence on crime and desistance patterns of the broader situational, collective, and sociological structures such as the overrepresentation of minorities and the impact of class on incarceration; or the amount of trauma, sexual abuse and violence in the lives of women who are incarcerated. We understand that this narrower individual focus is a limitation of our study that cannot be overcome within the confines of its methodology. Furthermore, our question about whether or not the provision of and engagement with HSR services at $X$ cost leads to individual desistance from crime tends to bestow an instrumental or "I-it" feel to the complex web of human relationships, engagements and meaning-making that we are trying to understand. It would be essential to support HSR in prison even if it did not have a direct influence on recidivism, because the prison chaplain's primary job is to protect, ensure and advance the constitutional and legal rights and responsibilities of women and men in prison to express, practice and grow in their way of making meaning whatever that 
path might be. The fact that this job can be carried out in a way that also promotes the rehabilitation mission of the Correctional system is a welcome bonus.

For a variety of reasons, including the need for additional high-quality studies, it is our opinion that the research on whether faith-informed and meaning-making approaches within the correctional process help people to lift themselves out of habits and identities that involve criminal behavior is encouraging but still inconclusive. Yes, we have some studies that show positive outcomes, but other studies have found nuanced impact or failed to find an impact. There is also great variation across the definition of interventions and the rigor of the existing studies. We do not have sufficient evidence to say that HSR engagement is an evidence-based practice in corrections. We can, however, say that it is an evidence-based practice for therapists to include HSR in therapy. The life-course and desistance literature has taught us that meaning-making is part of the process for people who successfully lift themselves out of crime. There are thousands of prison chaplains and volunteers across the US who are willing to engage and support incarcerated women in their journey of desistance. It is highly likely that fostering and supporting this diverse pursuit of meaning-making, motivation, social support and self-control significantly increases the capacity of the US criminal justice system in a cost-efficient way to be more compassionate, just, and effective.

Author Contributions: J.D. managed the set-up of the study, the data collection and cleaning, and he contributed to the writing. R.S. chose and executed the research methodology and analysis strategy and wrote the first draft of the article. S.H. collaborated with R.S. on the methodology and analysis. T.O. assisted Jeff with the set-up, data collection, and cleaning, and he contributed to the writing of the final draft.

Funding: The authors did not receive any funding for this research.

Conflicts of Interest: The authors declare no conflicts of interest.

\section{References and Notes}

Aos, Steve, Marna Miller, and Elizabeth Drake. 2006. Evidence-Based Adult Corrections Programs: What Works and What Does Not. Olympia: Washington State Institute For Public Policy.

Bales, William D., and Daniel P. Mears. 2008. Inmate Social Ties \& the Transition to Society: Does Visitation Reduce Recidivism? Journal of Research in Crime and Delinquency 45: 287-321.

Beck, Allen, Darrell Gilliard, Lawrence Greenfeld, Caroline Harlow, Thomas Hester, Louis Jankowski, Tracy Snell, James Stephan, and Danielle Morton. 1993. Survey of State Prison Inmates, 1991. Washington: U.S. Department of Justice.

Burnside, Jonathan, Joanna Adler, Nancy Loucks, and Gerry Rose. 2001. Kainos Community in Prisons: Report of an Evaluation. London: HM Prison Service England and Wales and Kainos Community.

Camp, Scott. 2008. The effect of faith program participation on prison misconduct: The life connections program. Journal of Criminal Justice 36: 389-95. [CrossRef]

Camp, Scott D., Jody Kliein-Safran, Okyun Karl Kwan, Dawn M. Daggett, and Victoria Joseph. 2006. An Exploration into Participation in a Faith-Based Program. Criminology and Public Policy 5: 529-50. [CrossRef]

Clear, Todd R., and Melvina T. Sumter. 2002. Prisoners, Prison, and Religion: Religion and Adjustment to Prison. Journal of Offender Rehabilitation 35: 127-59. [CrossRef]

Clear, Todd R., Bruce D. Stout, Harold Dammer, Linda Kelly, Patricia Hardyman, and Carol Shapiro. 1992. Prisoners, Prisons, and Religion: Final Report. Piscataway Township: School of Criminal Justice, Rutgers University.

Cnaan, Ram A., and Laura Amrofell. 1994. Mapping Volunteer Activitiy. Nonprofit and Volunteer Sector Quarterly 23: 335-51. [CrossRef]

Dammer, Harry R. 1992. Piety in Prison: An Ethnography of Religion in the Correctional Environment. Ph.D. dissertation, Rutgers The State University of New Jersey, Piscataway Township, NJ, USA.

Dammer, Harry R. 2002. The reasons for religious involvement in the correctional environment. Journal of Offender Rehabilitation 35: 35-58. [CrossRef]

Doblmeier, Martin. 2015. CHAPLAINS. Alexandria: Journey Films.

Dodson, Kimberly D., Leann N. Cabage, and Paul M. Klenowski. 2011. An evidence-based assessment of fatih based programs: Do faith-based programs 'work' to reduce recidivism. Journal of Offender Rehabilitation 50: 367-83. [CrossRef] 
Duwe, Grant, and Valerie Clark. 2011. Blessed Be the Social Tie That Binds: The Effects of Prison Visitation on Offender Recidivism. Criminal Juistice Policy Review 20: 1-26. [CrossRef]

Duwe, Grant, and Valerie Clark. 2017. The Rehabilitative Ideal Versus The Criminogemnic Reality: The Consequences of Warehousing Prisoners. Corrections 2: 41-69. [CrossRef]

Duwe, Grant, and Michelle King. 2013. Can Faith-BasedCorrectional Programs Work? An Outcome Evaluation of the InnerChange Freedom Initiative in Minnesota. International Journal of Offender Therapy and Comparative Criminology 57: 813-41. [CrossRef] [PubMed]

Dye, Meredith Huey, Ronald H. Aday, Lori Farney, and Jordan Raley. 2014. “The Rock I Cling To": Religious Engagement in the Lives of Life-Sentenced Women. The Prison Journal 94: 388-408. [CrossRef]

Epstein, David. 2009. Good without God: What a Billion Nonreligious People Do Believe. Cambridge: Harper Paperback.

Giordano, Peggy, Ryan D. Schroeder, and Patrick M. Seffrin. 2008. A Life-Course Perspective On Spirituality And Desistance From Crime. Criminology 46: 99-132. [CrossRef]

Gorsuch, Richard L., and G. Daniel Venable. 1983. Development of an "Age Universal" I-E Scale. Scientific Study of Religion 22: 181-87. [CrossRef]

Hill, Peter C., and Kenneth I. Pargament. 2013. Advances in the conceptu- alization and measurement of religion and spirituality-Implications for physical and mental health research. American Psychologist 58: 64-74. [CrossRef]

Idler, Ellen L., Mark A. Musick, Christopher G. Ellison, Linda K. George, Neal Krause, Marcia G. Ory, Kenneth I. Pargament, Lynda H. Powell, Lynn G. Underwood, and David R. Williams. 2003. Measuring multiple dimensions of religion and spirituality for health research: Conceptual background and findings from the 1998 general social survey. Research on Aging 25: 327-65. [CrossRef]

Independent Sector. 2016. The Value of Volunteer Time. Available online: https://independentsector.org/ resource/the-value-of-volunteer-time/ (accessed on 15 March 2018).

Jang, Sung Joon, and Aaron B. Franzen. 2013. Is Being “Spiritual” Enough Without Being Religious? A Study Of Violent And Property Crimes Among Emerging Adults. Criminology 51: 595-627. [CrossRef]

Johnson, Byron. R. 2004. Religious Programs and Recidivism Among Former Inmates In Prison Fellowship Programs: A Long-Term Follow-up study. Justice Quarterly 21: 330-54. [CrossRef]

Johnson, Byron R. 2011. More God, Less Crime: Why Faith Matters and How It Could Matter More. West Conshohocken: Templeton Press.

Kaufman vs. McCaughtry. 2005. US Court of Appeals, Seventh Circuit.

Kegan, Robert. 1998. In Over Our Heads: The Mental Demands of Modern Life. Cambridge: Harvard University Press. Kerley, Kent, Jessica Deitzer, and Lindsay Leban. 2014. Who is in Control? How Women in a Halfway House Use Faith to Recover from Drug Addiction. Religions 5: 852-70. [CrossRef]

Kruttschnitt, Candace, Rosemary Garner, and Amy Miller. 2000. Doing Her Own Time? Women's Responses to Prison in the Context of the Old and the New Penology. Criminology 3: 681-718. [CrossRef]

Levitt, Lacey, and Ann Booker Loper. 2009. The influence of religious participation on the adjustment of female inmates. American Journal of Orthopsychiatry 79: 1-7. [CrossRef] [PubMed]

LoBuglio, Stefan, and Martha Lymann. 2006. Whys and Hows of Measuring Jail Recidivism. Washington: The Urban Institute.

Mitchell, Meghan M., Kallee Spooner, Di Jia, and Yan Zhang. 2016. The effect of prison visitation on reentry success: A meta-analysis. Journal of Criminal Justice 47: 74-83. [CrossRef]

Morris, Ruth. 2017. Lowering Recidivism Through Spiritual Care. Interfaith Voices, December 7.

Mowen, Thomas J., Richard Stansfield, and John H. Boman. 2017. During, After, or Both? Isolating the Effect of Religious Support on Recidivism During Reentry. Journal of Quantitative Criminology, 1-23. [CrossRef]

Nidich, Sanford, Tom O'Connor, Thomas Rutledge, and Jeff B. Duncan. 2016. Reduced Trauma Symptoms and Perceived Stress in Male Prison Inmates through the Transcendental Meditation Program: A Randomized Controlled Trial. The Permanente Journal 20: 43. [PubMed]

Norcross, John C., and Bruce E. Wampold. 2011. What Works for Whom: Tailoring Psychotherapy to the Person. Journal of Clinical Psychology 67: 127-32. [CrossRef] [PubMed]

O'Connor, Tom, and Brad Bogue. 2010. Collaborating with the Community, Trained Volunteers and Faith Traditions: Building Social Capacity and Making Meaning to Support Desistance. In Offender Supervision: New Directions in Theory, Research and Practice. Edited by Fergus McNeill, Peter Rayner and Christopher J. Trotter. London: Willan Publishing Ltd., p. 28. 
O'Connor, Tom P., and Jeff B. Duncan. 2011. The Sociology of Humanist, Spiritual, and Religious Practice in Prison: Supporting Responsivity and Desistance from Crime. Religions 2: 590-610. [CrossRef]

O'Connor, Thomas P., and Michael Perreyclear. 2002. Prison Religion in Action and its Influence on Offender Rehabilitation. Journal of Offender Rehabilitation 35: 11-33. [CrossRef]

O'Connor, Thomas P., Yang Su, Patricia Ryan, Crystal Parikh, and Estrelda Alexander. 1997. Detroit Transition of Prisoners: Final Evaluation Report. Silver Spring: Center for Social Research.

O'Connor, Thomas P., Jeff B. Duncan, and Frank Quillard. 2006. Criminology and Religion: The Shape of an Authentic Dialogue. Criminology \& Public Policy 5: 559-70.

O'Connor, Tom, John Lehr, Sarah Lazzari, and Jeff B. Duncan. 2011. Prison and Re-entry Volunteers: An Overlooked, Creative and Cost Effective Source of Human Capital for Desistance. Washington: American Society of Criminology.

Oregon Department of Corrections. 2015. Research Brief: Automated Criminal Risk Score (ACRS). Salem: Oregon Department of Corrections.

Pew Forum on Religion and Public Life. 2008. U.S. Religious Landscape Survey: The Stronger Sex-Spiritually Speaking. Washington: Pew Forum on Religion and Public Life.

Pew Research Center. 2014. 2014 Religious Landscape Study. Washington: Pew Research Center.

Severance, Theresa A. 2005. "You Know Who You Can Go To": Cooperation and Exchange Between Incarcerated Women. The Prison Journal 85: 343-67. [CrossRef]

Stansfield, Richard, and Kirk Williams. 2014. Predicting Family Violence Recidivism Using the DVSI-R: Integrating Survival Analysis and Perpetrator Characteristics. Criminal Justice \& Behavior 41: 163-80.

Stansfield, Richard, Thomas J. Mowen, and Thomas P. O'Connor. 2017. Religious and Spiritual Support, Reentry, and Risk. Justice Quarterly 35: 254-79. [CrossRef]

Stark, Rodney. 2002. Physiology and Faith: Addressing the "Universal" Gender differences in Religious Commitment. Journal for the Scientific Study of Religion 41: 495-507. [CrossRef]

Sundt, Jody, and Francis T. Cullen. 1998. The Role of the Contemporary Prison Chaplain. The Prison Journal 78: 271-98. [CrossRef]

Sundt, Jody L., and Francis T. Cullen. 2002. Correctional Ideology of Prison Chaplains: A National Survey. Journal of Criminal Justice 30: 369-85. [CrossRef]

Taylor, Charles. 2007. A Secular Age. Cambridge: Belknap Press of Harvard University Press.

Trusty, Brittani, and Michael Eisenberg. 2003. Initial Process and Outcome Evaluation of the InnerChange Freedom Initiative: The Faith-Based Prison Program in TCDJ. Austin: Criminal Justice Policy Council.

Wilson, L. C., C. Wilson, S. R. Drummond, and K. Kelso. 2005. Promising Effects on the Reduction of Criminal Recidivism: An Evaluation of the Detroit Transition of Prisoner's Faith Based Initiative. Detroit: Wayne State University Press.

Worthington, Everett L., Joshua N. Hook, Don E. Davis, and Michael A. McDaniel. 2011. Religion and Spirituality. Journal of Clinical Psychology 67: 204-14. [CrossRef] [PubMed] 